\title{
Balance de la situación macroeconómica en 2010 y I Trimestre de 2011
}

\begin{abstract}
Rommel Rodríguez ${ }^{1}$
El artículo destaca que aunque la economía salvadoreña ha mostrado señales de recuperación en 2010, dichas señales son insuficientes para provocar la reactivación productiva que el país necesita.
\end{abstract}

The article highlights that while the Salvadoran economy has shown signs of recovery in 2010 , such conditions are not enough to reactivate the production this country needs

\section{Introducción}

A continuación se presenta un panorama de la situación macroeconómica del país, tanto en 2010 como en lo correspondiente a los primeros meses de 2011. En un primer momento, se observa la evolución de las variables del sector real de la economía, para posteriormente observar como ha sido el desempeño en el ámbito del comercio internacional.

Adicionalmente, se aborda la situación del sistema bancario, destacando la restricción crediticia que ha sufrido el país en los últimos años a pesar de que existe una abundante liquidez bancaria. En el campo fiscal, se aborda la recuperación de los ingresos tributarios y el mayor gasto social, acompañado, lamentablemente en un alza del endeudamiento público que se traduce en un mayor servicio de la deuda en los próximos años.

Así, en líneas generales se destaca que la economía salvadoreña mostró señales de recuperación en 2010. Si bien éstas son señales positivas, pues indican un leve auge en la actividad económica, son insuficientes para provocar la reactivación productiva que el país necesita. Por su parte, las expectativas para el 2011 son conservadoras, ya que se visualiza un año complejo, con una posible disminución de la demanda de exportaciones y crecimiento en las remesas familiares, a lo que se suma el repunte de los precios internacionales del petróleo, que ocasiona un fuerte impacto en todos los sectores de la economía salvadoreña. Asimismo, se prevé que la inversión privada continúe deprimida ante las restricciones de la banca al crédito y la situación de inseguridad que vive el país ${ }^{2}$. 


\section{Comportamiento del Sector Real}

En 2010, la economía salvadoreña creció $1.4 \%$, alcanzando los $\$ 21,214.7$ millones; cifras que muestran una leve -pero importante- recuperación después de la fuerte contracción que se registró en 2009, debido al impacto de la crisis internacional en El Salvador (Gráfico 1).

\section{Gráfico 1}

Evolución del Producto Interno Bruto

(US\$ millones y tasa de variación anual)

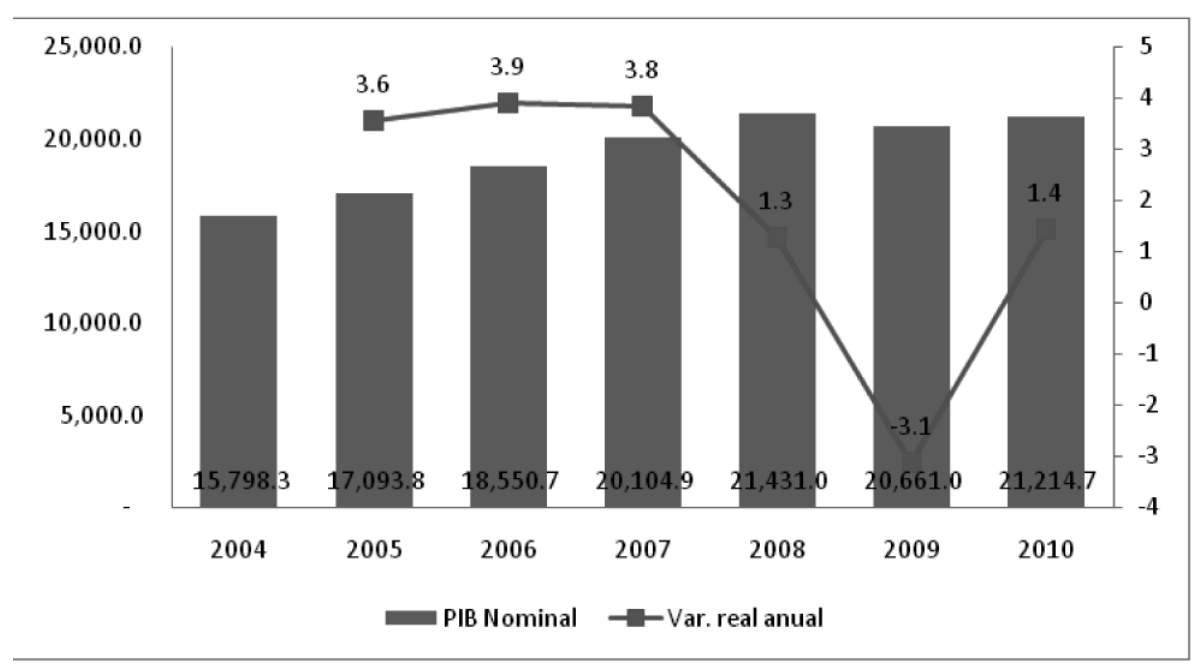

Fuente: BCR.

Lamentablemente, el auge que se experimentó el año pasado fue una recuperación por demás insignificante. Si se le ve desde una perspectiva de largo plazo, la tasa de crecimiento promedio en los últimos 5 años (20062010 ) ha sido de apenas $1.5 \%$, lo que se expresa en un dinamismo económico insuficiente para reactivar el aparato productivo y mejorar las condiciones de vida de la mayor parte de los salvadoreños.

No obstante, si bien esta recuperación resulta insuficiente, se debería tener presente que constituye un punto de inflexión con respecto al deterioro económico registrado en 2008 y 2009, cuando la economía mostró una tasa de variación del PIB de $1.3 \%$ y $-3.1 \%$, respectivamente. En este sentido, el auge económico podría traducirse, si está acompañado de las políticas económicas y sociales acertadas, en un relanzamiento del proceso de acumulación de capital que se traduzca en crecimiento sostenido en el mediano plazo.

Por otra parte, al observar las tendencias económicas más coyunturales, se nota que el mayor dinamismo económico con que cerró 2010 aún se mantiene 
a marzo de 2011, cuando el Índice de Volumen de Actividad Económica (IVAE) mostró una tasa variación anual de 3.6\%; la misma variación que se registró en diciembre del año pasado (Gráfico 2).

\section{Gráfico 2}

Tasa de variación anual del IVAE

(Porcentaje)

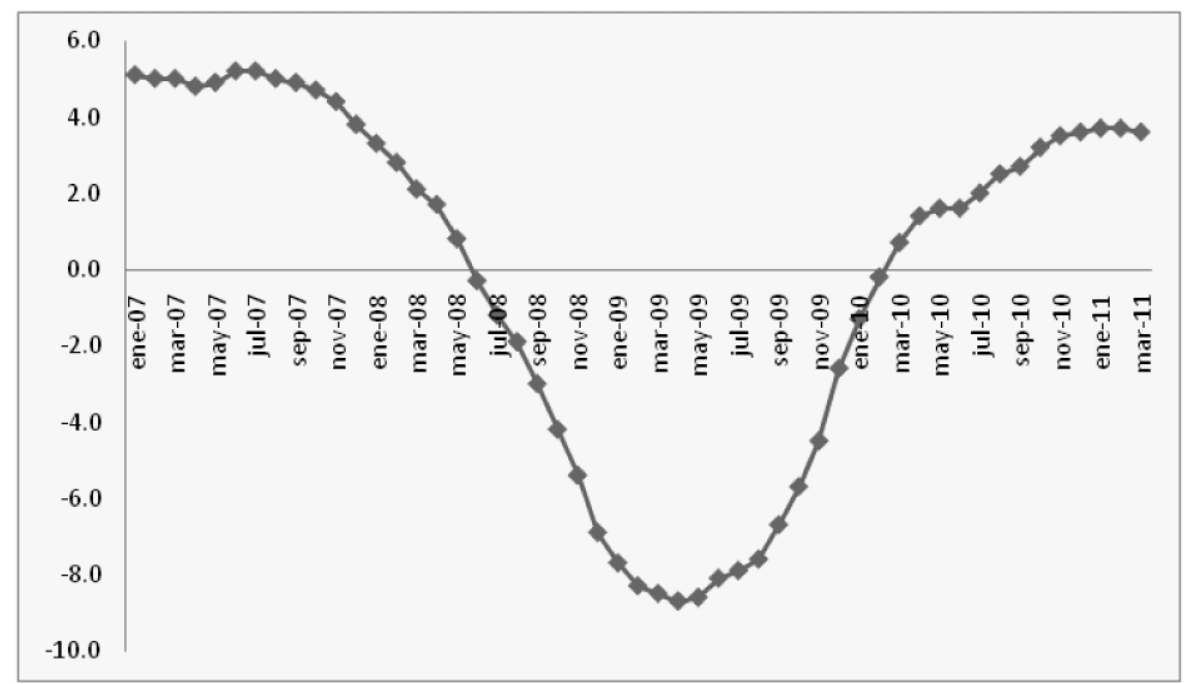

Fuente: BCR.

En la actualidad es importante destacar que si bien este proceso de recuperación parece mantenerse, resulta insuficiente si se desea reactivar la economía en el corto plazo. Para ello, sería necesario que la recuperación mostrara un IVAE creciendo mes a mes a tasas arriba del 5.0\%. De esta manera, se podría experimentar más vigor y ciertas mejoras en la economía familiar, siempre y cuando dicha recuperación no estuviera acompañada de una escalada de precios, como sucede actualmente.

En lo referente a la carestía de la vida, los precios han mostrado una tendencia alcista desde el cierre de 2010. Este incremento se debe fundamentalmente a la escalada de precios de los alimentos y el petróleo a nivel internacional. Dado que El Salvador es un país pequeño, sin suficiente producción agrícola para la autosustentabilidad, e importador total de combustibles, este incremento se está traduciendo en una escalada que se parece mucho a la que se experimentó en los primeros meses de 2008, previo al impacto internacional de la crisis en la economía salvadoreña (Gráfico 3) 
Gráfico 3

Tasa de variación anual del IPC

(Porcentaje)

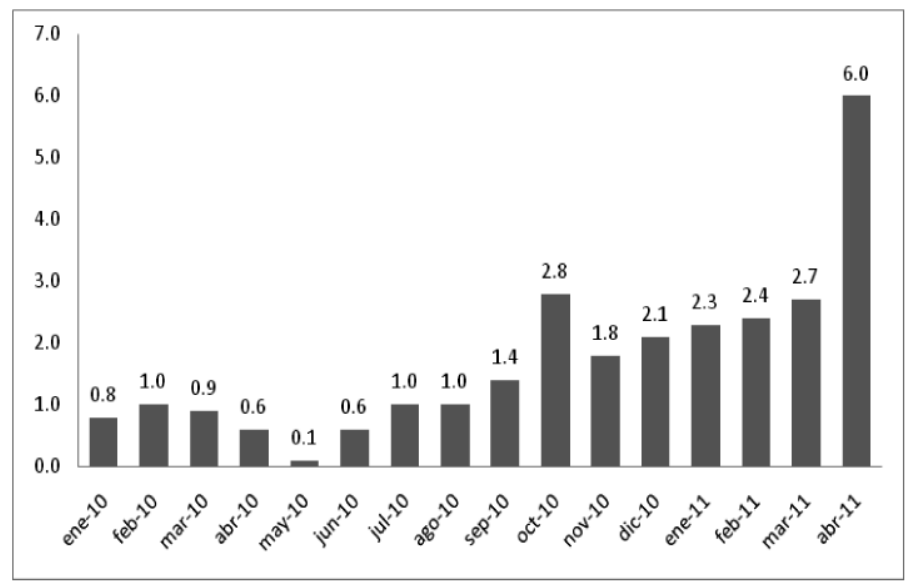

Fuente: BCR.

Al observar la evolución del Índice de Precios al Consumidor (IPC), se nota que el componente que tiene mayor peso en la determinación de la evolución de la inflación registrada en los primeros meses de 2011 ha sido el de "Alimentos y bebidas no alcohólicas". En vista de ello, el Estado salvadoreño se ha visto en la necesidad de importar granos básicos para incidir en los precios locales mediante el mayor aumento de la oferta local. No obstante, dicha medida no ha tenido éxito. Además, la medida ha sido criticada por la población porque dichos granos básicos son de una calidad deficiente a la acostumbrada en la dieta de los salvadoreños (Gráfico 4).

\section{Gráfico 4}

Tasa de variación del componente Alimentos y Bebidas No Alcohólicas

(Porcentaje)

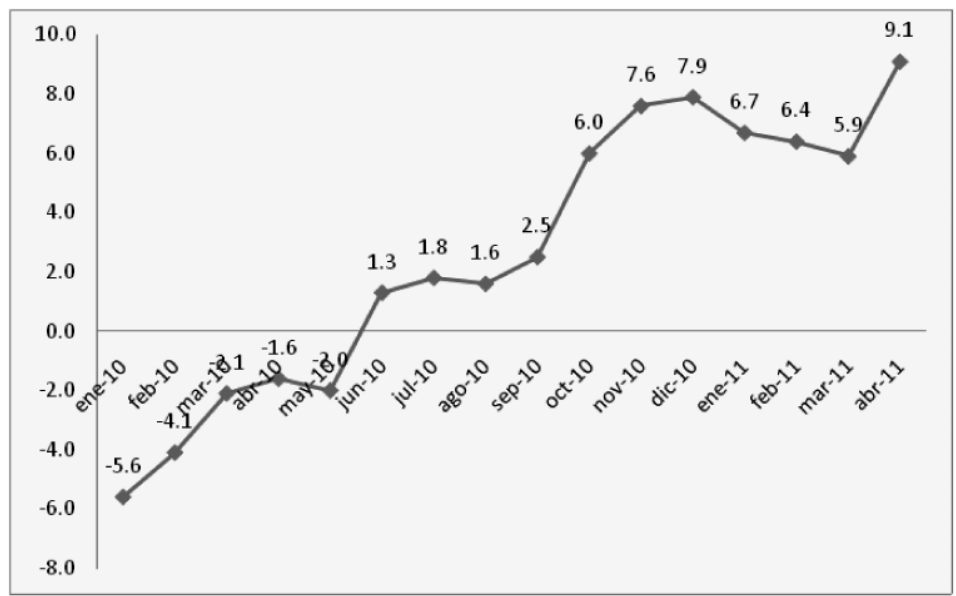

Fuente: BCR. 
Finalmente, para cerrar el panorama macroeconómico en lo que concierne al sector real, en 2010 se registró una recuperación en el empleo. Lamentablemente, la mayor parte de dicha recuperación no provino precisamente de un auge económico del sector privado formal, sino más bien de una expansión de las actividades del Estado, que ha crecido debido a la expansión de la política social.

Esto en sí mismo no es malo, siempre y cuando haya suficientes recursos para financiar dicha expansión; pero dada la fragilidad de las finanzas públicas y el lento proceso de recuperación, es probable que a futuro se registre un amplio recorte de empleados del sector público que ahora son financiados con recursos de endeudamiento público que, bajo el criterio de "refuerzo presupuestario", se destina para el gasto corriente estatal (Gráfico 5).

\section{Gráfico 5}

Evolución del empleo público y privado-formal

(No. de empleados y tasa de variación anual)

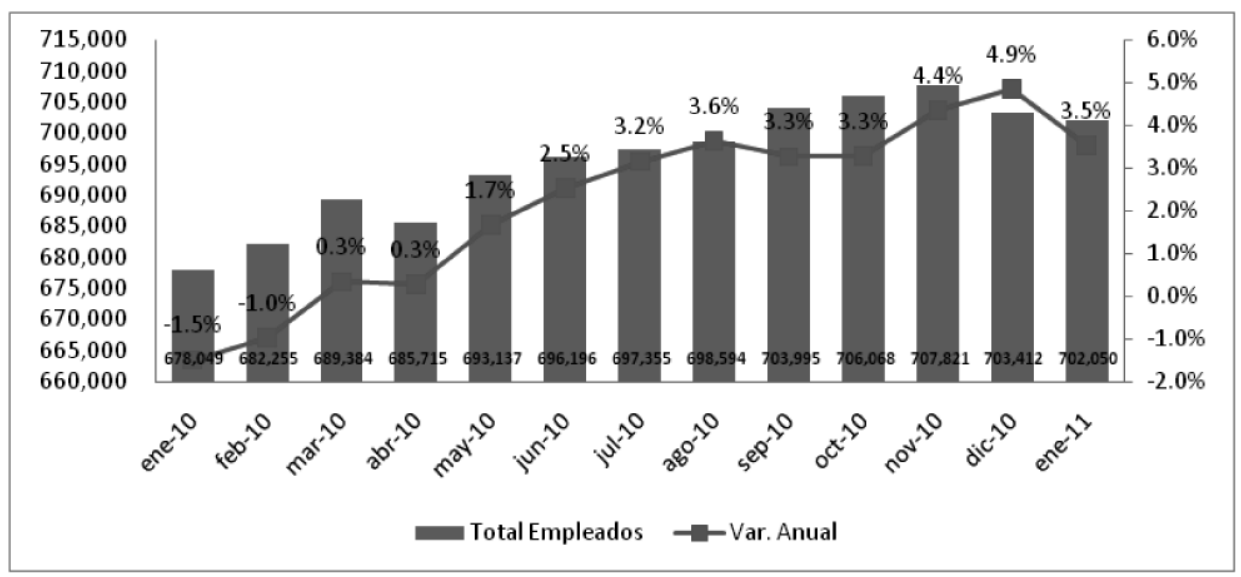

Fuente: ISSS.

Como se puede ver en el gráfico anterior, de enero a diciembre de 2010, el empleo pasó de 678,049 a 703,412 trabajadores, gracias al proceso de recuperación que mostró la economía el año pasado. No obstante, a enero de 2011, se registró un recorte de empleados que provino únicamente del sector público. Esto viene a dar más fuerza a la idea expuesta anteriormente: que por más que el sector público se expanda a través del número de empleados, estos son puestos inestables si el Estado no cuenta el mediano plazo con recursos suficientes para financiarlos.

\section{Comportamiento del Sector Externo}

La economía de El Salvador es una de las que tiene mayor grado de apertura en el Istmo centroamericano, principalmente por la política comercial que se impulso desde los inicios de la década de los noventa a través del proceso de 
apertura comercial que se ha consolidado hasta la actualidad con la firma de los tratados de libre comercio con México y Estados Unidos.

En este sentido, es muy importante tener presente que la economía nacional depende en gran medida de la evolución de la economía de Estados Unidos a través de las remesas y el flujo de las exportaciones e importaciones que determinan el saldo de la balanza comercial.

En 2010, las exportaciones alcanzaron los $\$ 4,472.0$ millones, representando un crecimiento anual del $17.8 \%$. Las importaciones, por su parte, arribaron a los $\$ 8,548.4$ millones, creciendo también un $17.8 \%$. Como resultado, se tiene un déficit comercial de $\$ 4,076.4$ millones, siendo éste $18.0 \%$ mayor que el registrado en 2009, cuando hubo una contracción debido a la caída severa de la demanda interna (Cuadro 1).

\section{Cuadro 1}

Balanxa Comercial

(En USS milones)

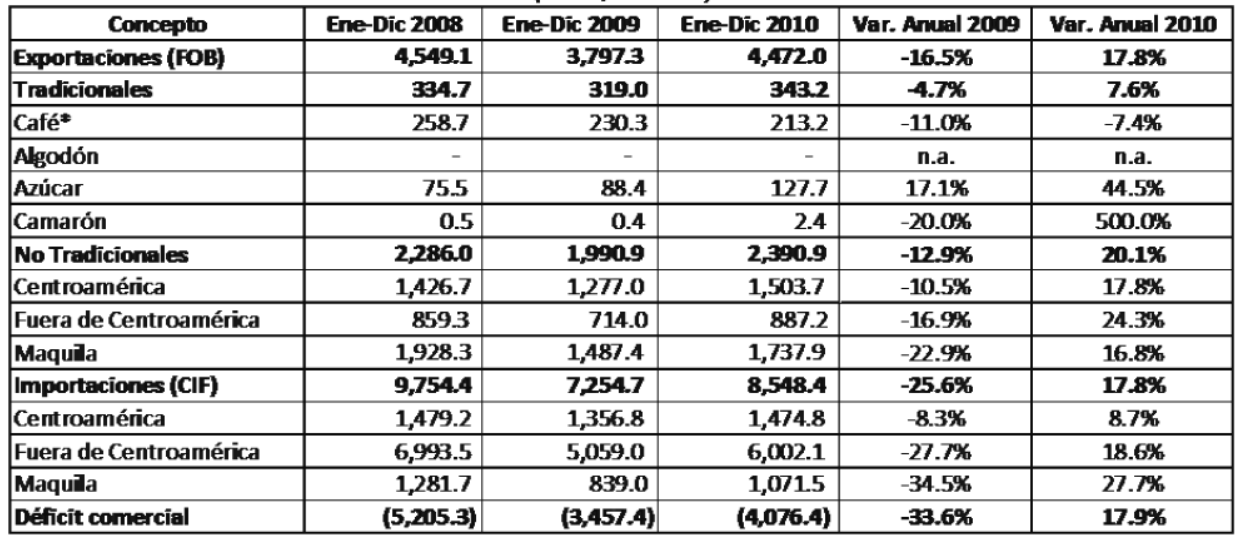

Fuente: elaboración propia con base en datos del BCR.

*Excluye café sohuble

n.a.: No aplica

Estos datos ponen de manifiesto un problema estructural: la economía salvadoreña es, a la postre, un importador neto, pues ha perdido en las última décadas su capacidad productiva que le permita alcanzar y sostener un superávit comercial. Es más, en época de auge económico, cuando el aparato productivo debería ser capaz de abastecer el mercado local y conquistar el mercado externo, es cuando contrariamente se registra mayor déficit.

Siempre en el ámbito del comercio internacional, en los primeros cuatro meses de 2011 , las exportaciones han alcanzado los $\$ 1,824.6$ millones, mientras que las importaciones son de $\$ 3,228.2$ millones. Durante estos meses, el sector más dinámico ha sido las exportaciones de bienes no tradicionales $(\$ 1,112.7$ millones), mientras que las tradicionales han realizado un bajo aporte a las exportaciones totales ( $\$ 330.5$ millones), aunque es importante destacar que 
la ventas de este último componente de la balanza comercial dependen sobre todo de las compras internacionales de café.

En el ámbito de las importaciones, la economía realizó compras en el mercado mundial por el monto de \$8,548.4 millones en 2010. Al desglosar las importaciones por tipo, se tiene que las importaciones más importantes han sido la compra de bienes de consumo $(\$ 2,937.6$ millones) y de bienes intermedios $(\$ 3,442.1$ millones) en el mercado internacional, pues representan el $34.4 \%$ y $40.3 \%$ de las importaciones totales, respectivamente (Cuadro 2).

\section{Cuadro 2}

Composición económica de las importaciones

(En US\$ millones y porcentaje)

\begin{tabular}{|l|r|c|r|r|r|c|}
\hline \multirow{2}{*}{\multicolumn{1}{c|}{ Concepto }} & \multicolumn{2}{|c|}{ Saldo a diciembre2008 } & \multicolumn{2}{c|}{ Saldo a diciembre2009 } & \multicolumn{2}{c|}{ Saldo a diciembre2010 } \\
\cline { 2 - 7 } & Monto & Composición & \multicolumn{1}{c|}{ Monto } & Composición & \multicolumn{1}{c|}{ Monto } & Composición \\
\hline Bienes de consumo & $2,974.1$ & $30.5 \%$ & $2,602.2$ & $35.9 \%$ & $2,937.6$ & $34.4 \%$ \\
\hline Bienes intermedios & $\mathbf{4 , 1 5 7 . 3}$ & $\mathbf{4 2 . 6 \%}$ & $2,801.6$ & $38.6 \%$ & $3,442.1$ & $40.3 \%$ \\
\hline Bienes de capital & $1,341.4$ & $13.8 \%$ & $1,011.9$ & $13.9 \%$ & $1,097.2$ & $12.8 \%$ \\
\hline Maquila & $1,281.6$ & $13.1 \%$ & 839.0 & $11.6 \%$ & $1,071.5$ & $12.5 \%$ \\
\hline Total & $\mathbf{9 , 7 5 4 . 5}$ & $100.0 \%$ & $7,254.7$ & $100.0 \%$ & $\mathbf{8 , 5 4 8 . 4}$ & $100.0 \%$ \\
\hline
\end{tabular}

Fuente: Elaboración propia con base en datos del BCR.

La mayor participación de las importaciones de bienes intermedios dan cuenta sobre la leve recuperación económica en 2010, especialmente cuando se le compara con 2009, cuando las importaciones de este tipo representaron alrededor del $38.6 \%$ de las importaciones totales.

Al mes de abril de 2011, el acumulado de importaciones muestra esta misma estructura, ya que las importaciones de bienes de consumo ( $\$ 1,072$ millones) y la de bienes intermedios $(\$ 1,455.0$ millones), continúan siendo las que tienen mayor peso en las importaciones totales del país.

Por otra parte, las remesas continúan aportando recursos al funcionamiento de la economía salvadoreña. El año pasado, el flujo de recursos de este tipo creció $1.3 \%$, lo cual implica una recuperación con respecto a 2009, pues en ese momento las remesas cayeron fuertemente debido al gran nivel de desempleo hispano en Estados Unidos. Pero en 2010 hubo señales de recuperación de la economía estadounidense, y eso se tradujo en una mayor entrada de flujos de remesas para los salvadoreños. 
Gráfico 6

Flujo anual de remesas

(US\$ millones y porcentaje)

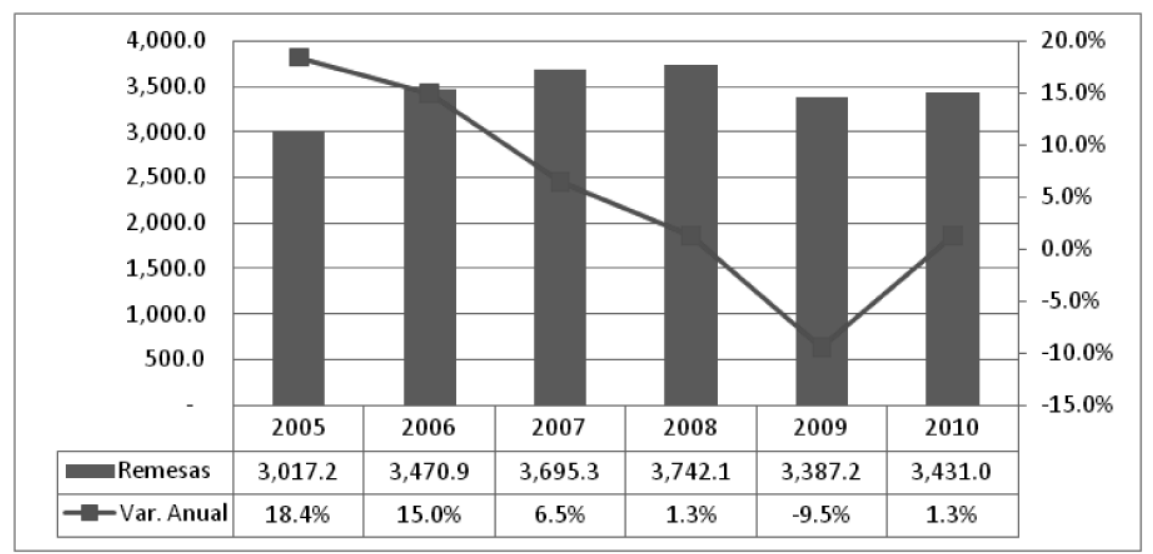

Fuente: BCR.

Para este nuevo año, el acumulado de remesas a abril de 2011 es $\$ 1,175.0$ millones, cantidad muy superior a la registrada en 2009 y 2010 , pero que aún no supera el nivel de 2008, época cuando aún no había impactado con toda su fuerza la crisis económica internacional en el mercado laboral estadounidense.

\section{Gráfico 7}

Acumulado de remesas entre enero y abril (US\$ millones y porcentaje)

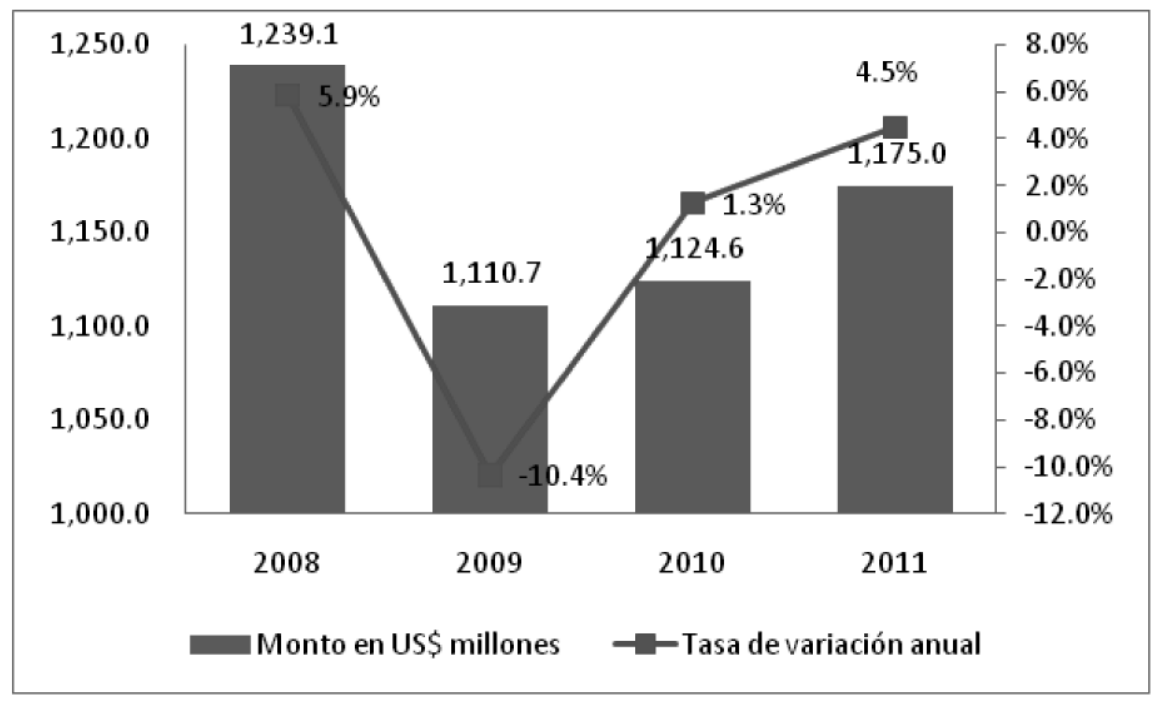

Fuente: BCR. 
La recuperación de este flujo de recursos es de suma importancia, y esto puede entenderse mediante dos vías: por un lado, y desde la perspectiva privada, las remesas son recursos para las familias que financian el gasto local y contribuyen a mantener cierto nivel de demanda, especialmente en aquellas familias de más escasos recursos, donde funcionan como paliativos a la pobreza de ingreso. Desde una perspectiva más amplia y macroeconómica, las remesas son una fuente clave de liquidez en una economía dolarizada. La falta de estos recursos se traduciría en una restricción severa de la demanda interna y externa, acompañada con seguridad de un alza en los tipos de interés. De hecho, la dolarización en El Salvador ha sido una medida de política viable -para algunos sectores más que otros-por el flujo de remesas que entran al país. Su escasez en el futuro o su reducción gradual hacen prácticamente insostenible la dolarización en el mediano y largo plazo.

\section{Comportamiento del Sector Financiero}

El sector financiero cumple un papel de suma importancia en la economía, pues "conecta" a las unidades que tienen superávit de préstamo neto con aquellas que tienen necesidades de financiamiento ${ }^{3}$. Es decir, la institucionalidad financiera de un país es la encargada de captar depósitos del público para posteriormente prestar dichos fondos a agentes económicos que requieren tales recursos para satisfacer sus necesidades de consumo y/o inversión en el corto, mediano y largo plazo.

Entre enero y diciembre de 2010, los depósitos pasaron de $\$ 9,102.8$ millones a $\$ 9,511,7$ millones; es decir, a diciembre la tasa de variación anual en el saldo total de depósitos aumentó 4.8\%, registrando un incremento importante en la liquidez bancaria. Al desglosar este incremento, se nota que la mayor parte de depósitos son fondos pactados a un año plazo (41.7\%) y cuentas de ahorro (28.4\%).

Para los primeros meses de 2011 esta tendencia se mantiene, pues si bien a abril el saldo de los depósitos totales ha caído levemente a $\$ 9,505.1$ millones, la tasa de variación anual a dicho mes sigue siendo alta (2.5\%). Como dato interesante, hay que destacar que ha habido una leve recomposición en los pasivos del sistema bancario, ya que los depósitos a un año plazo continúan teniendo el mayor peso (38.7\%), y los depósitos en cuenta corriente y ahorro tiene el mismo peso en el saldo total de depósitos en el sistema bancario (29.1\%).

Por otra parte, con respecto a los activos es importante destacar que el saldo total de préstamos no muestra señales claras de recuperación. Esto se debe a dos razones: por una menor demanda de crédito debido a la incertidumbre que impera en el ambiente económico, y debido a las dificultades propias que ha puesto la banca privada para la aprobación de préstamos. 
Así, a diciembre de 2010 , el saldo total de préstamo alcanzó los $\$ 8,402.2$ millones, cifra que representó una caída de $2.7 \%$. Al desglosar, se nota que los ámbitos que muestran un mayor peso en dicho saldo son los préstamos al consumo $(28.1 \%)$, adquisición de vivienda $(25.7 \%$ ) y comercio $(14.5 \%)$.

Entre enero y abril de 2011, el saldo de préstamos totales del sistema bancario creció levemente a $\$ 8,435.5$ millones. Sin embargo, a pesar de esta recuperación en términos nominales, la tasa de variación anual muestra una contracción de $1.4 \%$, por lo que resulta totalmente insuficiente para expandir considerablemente el crédito, y se traduzca en un fuerte auge de la demanda interna que dinamice la economía salvadoreña.

Para visualizar con mayor claridad esta dinámica del sistema bancario, el Gráfico 7 muestra la evolución del saldo total de préstamos vs el saldo total de depósitos, como también el exceso de liquidez que se ha estado registrando en los últimos dos años.

\section{Gráfico 7}

Evolución del saldo de depósitos y préstamos bancarios (US\$ millones)

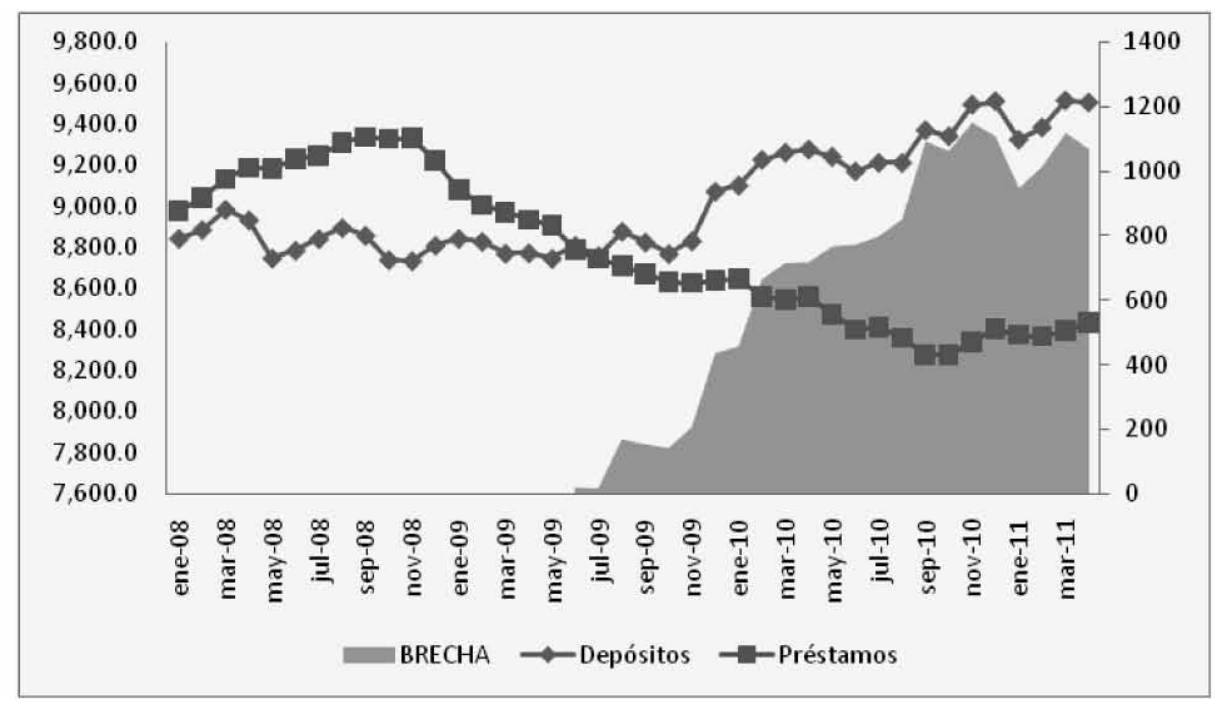

Fuente: SSF.

Como se puede ver en la gráfico anterior, la "brecha" entre depósitos y préstamos es de alrededor de $\$ 1,000$ millones a abril de 2011. Este exceso de liquidez bancaria es el que no se logra colocar en préstamos a pesar de que en los últimos meses se ha registrado una caída en las tasas de interés. Esto es una situación de particular importancia, pues indica que los agentes económico no están reaccionando ante el estímulo del mercado bancario y también habla de las delicadas condiciones económicas que atraviesa el país. 
Gráfico 8

Tasas de interés del Sistema Bancario

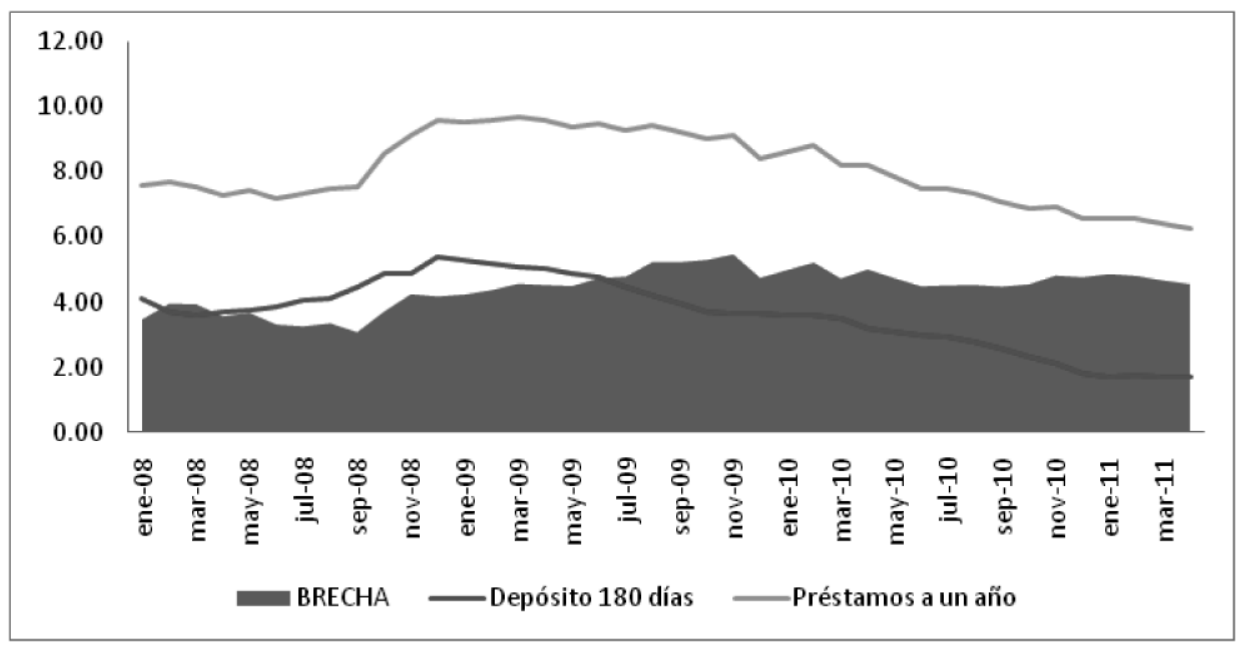

Fuente: BCR.

Con más detalle, a abril de 2011, la tasa de interés por depósitos a 180 días cayó a 1.68, mientras la tasa para préstamos a un año plazo también cayó a 6.26 (Gráfico 8). Esta reducción en ambos tipos de interés ha sido casi en sincronía, lo que se ha traducido en una brecha entre tasas que no varía sustancialmente. A pesar de esta caída en la tasa de interés, el crédito al sector privado no se reactiva, lo que representa un grave entrampamiento a la recuperación económica que el país necesita.

\section{Comportamiento del Sector Fiscal}

En el ámbito fiscal ha sucedió una recuperación gradual de los ingresos el Estado debido al mayor dinamismo que mostró la economía durante 2010. No obstante, a pesar de esta recuperación, las necesidades de gasto también han crecido considerablemente en los últimos años, lo que ha presionado a un incremento por demás importante el nivel de endeudamiento del Estado.

En detalle, en 2010, el total de ingresos y donaciones que recibió el Estado a nivel de Sector Público No Financiero (SPNF) fue de $\$ 3,970.1$ millones, es decir, $\$ 386.1$ millones más que lo que se obtuvo en concepto de ingresos total en 2009 , año en que el impacto de la crisis representó una caída abrupta en la actividad económica. Por esa razón se registro en dicho año una menor recaudación en IVA y Renta, impuesto que son los pilares fundamentales de la recaudación tributaria del país.

Por su parte, el gasto público -también a nivel de SPNF-alcanzó en 2010 los $\$ 4,889.8$ millones, es decir, $\$ 134.8$ millones más que lo registrado en 2009. 
Así las cosas, la diferencia entre ingresos y gastos del Estado generó un déficit fiscal de $\$ 919.7$ millones, equivalente a $4.3 \%$ del PIB (Cuadro 3). Es importante llamar la atención que el déficit fiscal y el déficit comercial constituyen una fuerte salida de recursos financieros que afectan el nivel de liquidez con la que cuenta el país.

\section{Cuadro 3}

Resultado del SPFF a diciembre de 2010

(En US\$ mines)

\begin{tabular}{|c|c|c|c|c|c|}
\hline Concepto & Ene-Dic 2008 & Ene-Dic 2009 & Ene-Dic 2010 & Vtr and 2009 & Y. And 2010 \\
\hline 1 hresos r Domocions & $4,016.3$ & 3,5840 & 3,9701 & [4323] & 386.1 \\
\hline 1.1 Ingresos Corrientes & 3,9633 & $3,4 \sqrt{5.2}$ & 3,8055 & [488.1) & 330.3 \\
\hline 1.1.1 Tíbutarios [Netos] & $2,885.8$ & 2,6094 & 2,8816 & [276.4)] & $2 \pi 2$ \\
\hline 1.12 Contribuciones a b Sequrichd Social & 351.9 & 3546 & 3663 & 27 & 11.7 \\
\hline 1.13 No Tributarios & 267.5 & 2183 & 2847 & (492) & 66.4 \\
\hline 1.14 Superivit de 0peración de Empresa Públicas & 1739 & 1082 & 1047 & {$[65.7)$} & [35] \\
\hline 1.15 Transfiencias de Francierax Públicas & 2843 & 1846 & 1681 & [99.7] & [16.5) \\
\hline 12 hquesos de Gapital & 0.1 & 0.1 & 0.2 & - & $\mathbf{0 1}$ \\
\hline 13 Donaciones del Exterior & 529 & 1087 & 1644 & 55.8 & 5.7 \\
\hline 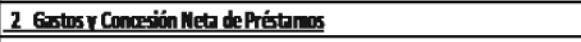 & $4,699.7$ & 4,7555 & $4,898.8$ & 55.8 & 134.3 \\
\hline 2.1 Gastos Corrientes & 4,0386 & 4,1133 & 4,2127 & 74.7 & 9.4 \\
\hline 211 Consumo & 2,3508 & 2,5331 & 2,6540 & 1823 & 1009 \\
\hline 212 Intereses & 5196 & 5309 & 5080 & 113 & (22.9) \\
\hline 213 Transferencix Corrientes* & 1,1682 & 1,0493 & 1,0507 & [1189] & 14 \\
\hline 2.2 Gastos de Capital & 661.7 & 6A31 & 677.6 & [186] & 345 \\
\hline 221 mmersín Bruta & 5821 & 581.3 & 6210 & [0.8] & 3.7.7 \\
\hline 222 Transferencias de Gapital & 79.7 & 619 & 566 & [17.8) & [53] \\
\hline 23 Concesión Netade Préstamos & {$[0.6]$} & [0.9] & [0.5] & [03] & 04 \\
\hline 3 Ahorro Corriente incluye pensiones y fideicomisos & (75.3) & $(638.1)$ & $(407.2)$ & [5628] & 2309 \\
\hline 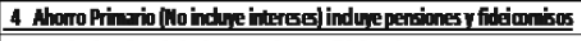 & 443 & [1072] & 100.8 & [5515] & 2080 \\
\hline 5 Rssuledo Pricrio indue persions rfideicon isos & [163.8] & [640.6] & [411]] & [476.8] & 2889 \\
\hline 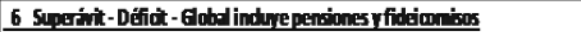 & [683.4) & {$[1,1715]$} & {$[919.7]$} & [488.1] & 2518 \\
\hline
\end{tabular}

Fuente edaboración propia con base en mitos del BCR

*inchyegasto en pensiones

Por otra parte, es de suma importancia llamar la atención sobre el rápido incremento del endeudamiento público. A abril de 2011, la deuda total del Estado es de $\$ 12,776.0$ millones, es decir, en tan sólo un año -con respecto a abril de 2010-, la deuda creció en $\$ 1,810.7$ millones. Esto implica, sin duda, una mayor carga fiscal en el futuro. De ahí la importancia de una recuperación económica que acompañada de una reforma tributaria consensuada -el llamado pacto fiscal- proporcione al Estado los recursos necesarios para sostener financieramente al país (Gráfico 9). 
Gráfico 9

Deuda pública total

(US\$ millones)

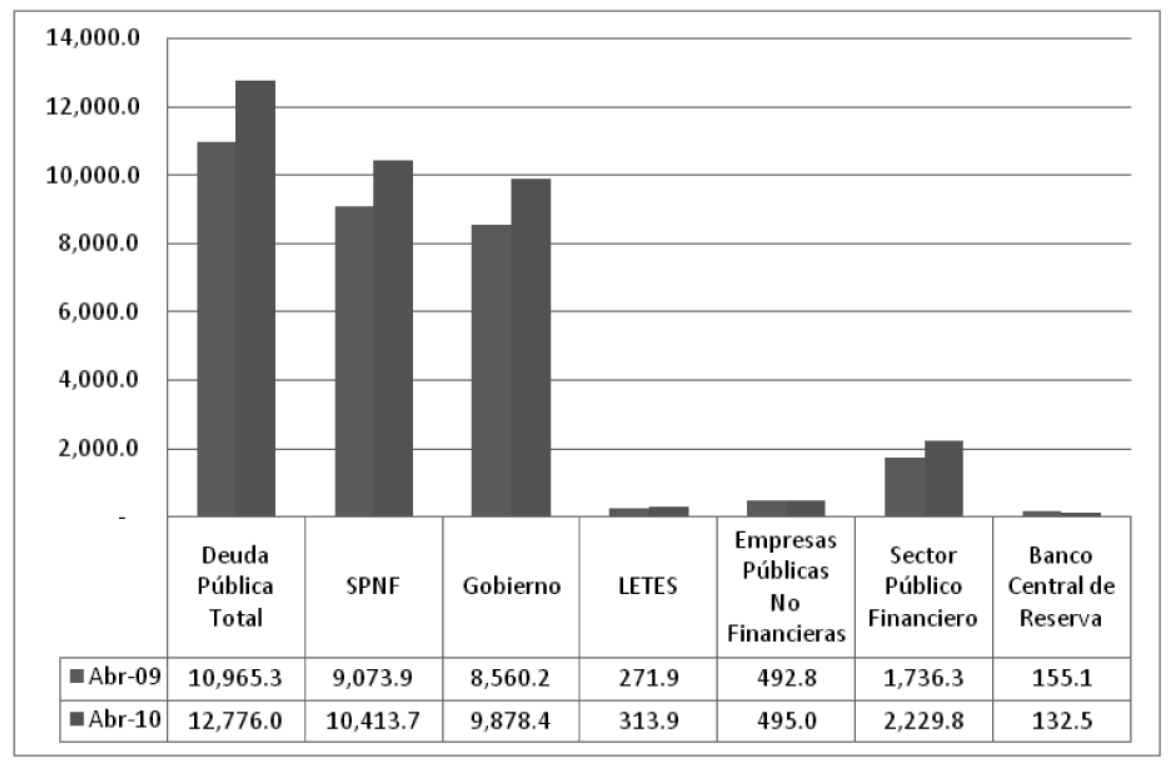

Fuente: BCR.

Al desglosar la deuda total del Estado, se nota que el mayor nivel de endeudamiento en la estructura económico-administrativa proviene del Gobierno Central ( $\$ 1,318.2$ millones). Hay que decir con toda franqueza que gran parte de estos recursos han sido utilizados para abrir nuevas plazas con miras a expandir el gasto social. No obstante, esta tendencia no es sostenible, pues llevaría a un incremento acelerado del déficit fiscal y del endeudamiento público.

\section{A modo de conclusión}

La economía salvadoreña aún se encuentra en un proceso de recuperación que está lejos de consolidarse. Para que esto suceda, es necesario que el leve dinamismo económico que se registró en 2010, y que aún se mantiene en los primeros meses de 2011, pueda verse acompañado de políticas económicas y sociales atinadas.

En el ámbito económico, actualmente se elaboran dos propuestas que podrían contribuir a generar mayor crecimiento: la Ley del Sistema Financiero para el Desarrollo - que está siendo estudiada en la Asamblea Legislativa- y la Ley de los Asocios Público Privados -que actualmente se discute y trabaja al interior del Consejo Económico Social (CES)-. 
En el campo social, el gobierno está en proceso de expansión de la política social, mediante la construcción de nuevas viviendas, ampliación del programa Comunidades Solidarias y más recursos para la pensión por vejez al adulto mayor. Esto, además, de un mayor gasto de las áreas de Educación y Salud. No obstante, es necesario destacar que esta expansión es insostenible si no se cuenta con más recursos en los próximos años. Esto sólo se puede alcanzar mediante el establecimiento de un Acuerdo Fiscal entre los diferentes sectores de la sociedad, donde se establezcan las apuestas estratégicas que el país se necesita y exista un verdadero compromiso de financiarlas.

Además, no debe olvidarse que un elemento clave para la recuperación de la economía es el ataque efectivo a las condiciones que originan la violencia social. Para ello, al igual que sucede con el gasto social, se necesita una mayor cantidad de recursos, por lo que el mandatario salvadoreño, Mauricio Funes, se ha mostrado interesado en establecer un impuesto a los grandes capitales. Esta medida si bien es interesante, debe estar acompañada de un plan estratégico para atacar la inseguridad, como también con una reorganización administrativa que permita un uso más eficiente de estos recursos. Más dinero acompañado con un gasto ineficiente sólo se puede traducir en política públicas fallidas que no se traducen en beneficios concretos a la población.

No obstante el tema de la seguridad es importante, hay que resaltar que para generar mejores condiciones para el crecimiento es más importante el gasto en capital humano que se traduzca en aumentos en la productividad. Por ello, el Estado y las empresas deben ponerse de acuerdo en destinar más recursos para la educación. De nueva cuenta aparece acá el tema del Acuerdo Fiscal: más recursos con gasto más eficiente para atender las necesidades de más elementales de la población: salud, educación, vivienda, entre otras. 